aerobic conditions in order to maintain its quality. Long term storage studies should be conducted to investigate the optimum timing and storage conditions of vermicompost for enhanced benefits in field application.

1. Nada, W. M., Van Rensburg, L., Claassens, S. and Blumenstein, O., Effect of vermicompost on soil and plant properties of coal spoil in the Lusatian Region (Eastern Germany). Commun. Soil Sci. Plant Anal., 2011, 42, 1945-1957.

2. Wang, X. X., Zhao, F., Zhang, G., Zhang, Y. and Yang, L., Vermicompost improves tomato yield and quality and the biochemical properties of soils with different tomato planting history in a greenhouse study. Front. Plant Sci., 2017, 8, 1978.

3. Karimi, H., Mokhtari, M., Salehi, F., Sojoudi, S. and Ebrahimi, A., Changes in microbial pathogen dynamics during vermicomposting mixture of cow manure-organic solid waste and cow manure-sewage sludge. Int. J. Recycl. Org. Waste Agric., 2017, 6, $57-61$.

4. Chaoui, H. I., Zibilske, L. M. and Ohnot, Effects of earthworms cast and compost on soil microbial activity and plant nutrient availability. Soil Biol. Biochem., 2003, 35, 295-302.

5. Guerrero, R. D., Vermicompost production and its use for crop production in the Philippines. Int. J. Global Env. Issue., 2010, 10(3/4), 378-383.

6. Rekha, G. S., Kaleena, R. K., Elumalai, D., Srikumaran, M. P. and Maheswari, V. N., Effects of vermicompost and plant growth enhancers on the exo-morphological features of Capsicum annum (Linn.) Hepper. Int. J. Recycl. Org. Waste Agric., 2018, 7(1), $83-88$.

7. Ramnarain, Y. I., Ori, L. and Ansari, A. A., Effect of the use of vermicompost on the plant growth parameters of Pak Choi (Brassica rapa var. chinensis) and on the soil structure in Suriname. J. Global Agric. Ecol., 2018, 8(1), 8-15.

8. Decaens, T., Rangel, A. F., Asakawa, N. and Thomas, R. J., Carbon and nitrogen dynamics in ageing earthworm casts in grasslands of the eastern plains of Colombia. Biol. Fert. Soils, 1999, 30, 20-28.

9. Karthikeyan, M., Gajalakshmi, S. and Abbasi, S. A., Effect of storage on the properties of vermicompost generated from paper waste: with focus on pre drying and extent of sealing. Int. J. Energy Environ. Eng., 2014, 5, 291-301.

10. Harit, A. K., Karthikeyan, M., Gajalakshmi, S. and Abbasi, S. A., Effect of storage on some physical and chemical characteristics of vermicast. J. Appl. Hortic., 2014, 16(2), 112-116.

11. Singh, A. and Sharma, S., Composting of a crop residue through treatment with microorganisms and subsequent vermicomposting. Biores. Technol., 2002, 85, 107-111.

12. Sharma, P., Sharma, H. C., Singh, P. and Prasad, R., Vermicomposts and biofertilizers for improved tomato productivity and soil properties in degraded soils of lower Himalayas. Indian J. Soil Conserv., 2013, 41, 274-278.

13. Tejada, M., Gómez, I., Hernández, T. and García, C., Utilization of vermicomposts in soil restoration: effects on soil biological properties. Soil Sci. Soc. Am. J., 2010, 74, 525-532.

ACKNOWLEDGEMENTS. We are grateful to Director, ICAR-Indian Institute of Soil and Water Conservation, Dehradun for permission to conduct these studies at research centre, Chandigarh. The financial assistance by Dolphin College, Chandigarh is gratefully acknowledged.

Received 11 January 2019; revised accepted 24 September 2019

\section{A comparative study of antioxidant activity and total phenolic content of fresh juices of some common Indian fruits with their commercial counterparts}

\author{
Brototi Roy, Jyoti Singh* and Tanya Dewan \\ Department of Zoology, Maitreyi College, Chanakyapuri, \\ Delhi 110 021, India
}

Oxidative stress caused by overproduction of free radicals has been implicated in the pathogenesis of various chronic diseases like cancer, diabetes, cardiovascular diseases, and neurodegenerative and immunological disorders. Physiologically, these free radicals are scavenged continuously by numerous beneficial substances known as antioxidants. Fruits are rich in antioxidants such as ascorbic acid, flavonoids and polyphenols that strengthen our immunity and help us maintain good health. In recent times, there has been an increasing trend to supplement our diet with packaged fruit juices. In light of this, the present study aims to compare the antioxidant activity and total phenolic content (TPC) of commonly available fresh juices of some fruits found in the Indian subcontinent with their commercial counterparts, available in two popular brands. Folin-Ciocalteu method was used to determine TPC, while ferric reducing antioxidant power assay was performed to evaluate the antioxidant activity of fruit juices. Among fresh juices, the highest antioxidant property and TPC was found in pomegranate followed by litchi. Amongst packed fruit juices, the antioxidant property and TPC was highest in pomegranate and lowest in apple. However, when compared with fresh fruit juices, the antioxidant activity as well as TPC of commercial juices were observed to be significantly less in all cases. These observations prompt serious rethinking on the use of commercial juices as a source of antioxidants.

Keywords: Antioxidant activity, fresh fruits, packaged juices, total phenolic content.

REACTIVE oxygen species are known to cause various types of damages to biological systems leading to many non-communicable diseases ${ }^{1-3}$. Several epidemiological studies as well meta-analysis have revealed the protective effect of fruit juices against cancer, stroke and other noncommunicable diseases that can be related to the antioxidants found in these fruits. These antioxidants play a crucial role in the maintenance of health and prevention of various pathological conditions such as cardiovascular and neurological diseases, age-related disorders, cancer, etc. $^{4-6}$. A report published in 2003 by the World Health

*For correspondence. (e-mail: jyoti@maitreyi.du.ac.in) 


\section{RESEARCH COMMUNICATIONS}

Organization (WHO) on diet, nutrition and prevention of chronic diseases mentions that insufficient intake of fruits and vegetables is estimated to cause around $14 \%$ of all gastrointestinal cancer deaths, about $11 \%$ of ischaemic heart disease-related deaths and about $9 \%$ of strokerelated deaths. According to this report, low fruit and vegetable intake is also among the top 10 risk factors contributing to overall mortality ${ }^{7}$. Furthermore, WHO recommends a daily intake of at least $400 \mathrm{~g}$ of fruits (or five daily servings with an average serving size of $80 \mathrm{~g}$ ). Surprisingly, even though India is among one of the largest producers and exporters of fruits, a study based on secondary information analysis and survey of 1001 consumers spread across many states reports that only $21.2 \%$ of Indians consume fruits and vegetables ${ }^{8}$.

Moreover, in developing countries like India, people are witnessing a sudden change in their lifestyles and thus adopting new instant food habits. With rapid urbanization, surge in income and less availability of time, more and more consumers are relying on packaged fruit juices in comparison to fresh fruits. This trend has driven the food industry to develop new functional foods and beverages with added health benefits. Antioxidants in foods and beverages have become increasingly popular because of their potential health benefits as advertised by their manufacturers. According to a recent report, the branded fruit juice market in India is estimated to be around Rs 1100 crores. However, there are several disadvantages of choosing packaged juices over fresh fruit juices like high calorie intake, high sugar content and depleted dietary fibres. The advertised multivitamins in packaged juices are normally synthetic and added during the processing of fruit juices. Additionally, fruit mashing, filtration, heat pasteurization and storage are expected to alter the antioxidant properties of commercially available fruit juices ${ }^{9}$. Some of the synthetic antioxidants such as butylated hydroxytoluene, butylated hydroxyanisole and tertbutylhydroxyquinone used as permitted preservatives in commercial beverages, when present in high concentrations, may cause genotoxicity and carcinogenicity ${ }^{10}$. Surprisingly, although the antioxidant activities of many fruits available in India are regularly being estimated, no effort has been made to compare the antioxidant property of packaged fruit juices with their fresh juice counterparts.

In view of this, the present study was undertaken to make a comparison between antioxidant properties of fresh and packaged fruit juices. The total phenol content (TPC) was also measured to substantiate the antioxidant capacity. To authenticate the study, packaged fruit juices of two popular brands in India were used. The study also aims to provide an insight to consumers about the impact of substituting fresh fruit juices with their commercial counterparts as a source of antioxidants.

2,4,6-Tripyridyl-s-triazine (TPTZ), Folin-Ciocalteu reagent (FCR), gallic acid, ascorbic acid, sodium acetate, glacial acetic acid, ferric chloride and sodium carbonate were purchased from Merck, India. All the chemicals used were of analytical grade.

Fruit samples of high quality, including mango, litchi, pomegranate, orange, pineapple and apple were purchased from the local supermarket and stored in a refrigerator $\left(5^{\circ} \mathrm{C}\right)$ until processing. The packaged juices of two popular brands were also bought from the supermarket and coded accordingly for their further usage.

The fruits were washed under running tap water and air-dried before preparation of samples. Each fruit was peeled and divided into small pieces. The fresh juices were collected by grinding these pieces and careful handsqueezing using double-fold muslin cloth. The pomegranate was processed in two different ways. In one of the methods, only aril, including seeds was used, whereas in the other method, aril, pellicle and seeds were processed. To avoid the presence of insoluble components in the juices, the samples were diluted as required and filtered thoroughly.

Ferric ion reducing antioxidant power (FRAP) takes advantage of electron transfer reactions. Here ferric salt, $\mathrm{Fe}(\mathrm{III})(\mathrm{TPTZ})_{2} \mathrm{Cl}_{3}$ is used as an oxidant. The reagent was prepared freshly using the modified method of Benzie and Strain $^{11}$. Briefly, acetate buffer (300 mM, pH 3.6), $10 \mathrm{mM}$ TPTZ in $40 \mathrm{mM} \mathrm{HCl}$ and $20 \mathrm{mM} \mathrm{FeCl}_{3}$ stock solutions were prepared and mixed in the ratio $10: 1: 1$ to obtain working FRAP solution. The sample was used undiluted, as mentioned in Abountiolas and Nunes ${ }^{12}$. In a test tube, $0.4 \mathrm{ml}$ of sample was mixed with $1.6 \mathrm{ml}$ of working FRAP reagent. The tubes were further incubated at $37^{\circ} \mathrm{C}$ for $30 \mathrm{~min}$. The optical density of the coloured ferrous tripyridyltriazine complex in the solution was measured at $590 \mathrm{~nm}$. Ascorbic acid in the range 10-80 $\mu \mathrm{g}$ was used as standard. The results were expressed as $\mathrm{mg} / 100 \mathrm{ml}$ of ascorbic acid.

TPC was determined using modified FCR method of Singleton and Rossi ${ }^{13}$, and Sasic-Keskin et al. ${ }^{14}$. In brief, fresh fruit and packaged juices were diluted 25 times using distilled water. Next, $0.2 \mathrm{ml}$ of this diluted sample was taken in a test tube and mixed with $1: 10$ diluted FCR. The contents of the tubes were vortexed and allowed to stand for $10 \mathrm{~min}$. Then, $0.8 \mathrm{ml}$ of sodium carbonate solution $(7.5 \% \mathrm{w} / \mathrm{v})$ was added and incubated at room temperature for $30 \mathrm{~min}$. The absorbance of resulting solution was measured at $700 \mathrm{~nm}$. TPC was expressed as GAE (gallic acid equivalents) in $\mathrm{mg} / 100 \mathrm{ml}$ of fruit sample. The concentration of polyphenols was determined from the standard curve of gallic acid in the range $2-16 \mu \mathrm{g} / \mathrm{ml}$.

All the samples of fresh fruit and packed juices were run in triplicate. Standard deviation and standard error of mean were calculated and expressed in respective graphs. Analysis of variance was done using GraphPad Prism Version 5. Also, $P$-value $<0.0001$ was considered to be significant.

Several methods are used to assess antioxidant properties of biological materials. The most commonly used 


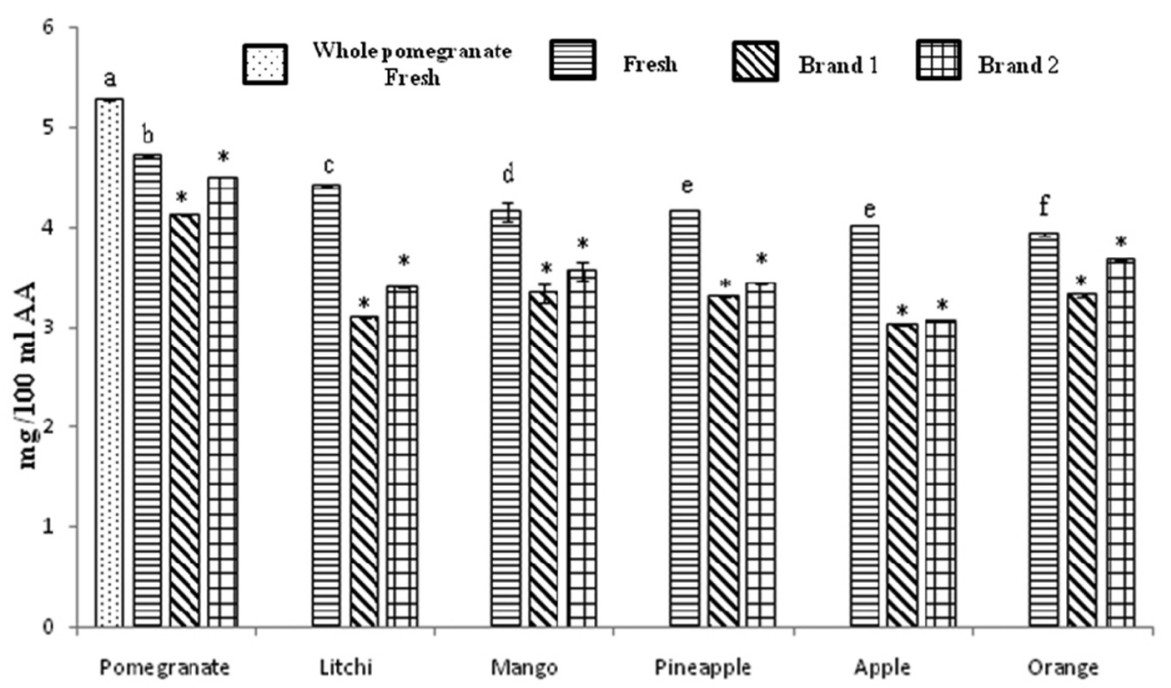

Figure 1. Ferric ion reducing antioxidant power (FRAP) values (mg/100 $\mathrm{ml}$ ascorbic acid) of various fresh fruit juices and packaged juices. Each value represents mean \pm SEM, $n=5$. Values with different superscripts (a-f) differ significantly at $P<0.0001$. The FRAP values of packaged juices marked with $(*)$ are significantly $(P<0.001)$ different compared to their fresh fruit counterparts.

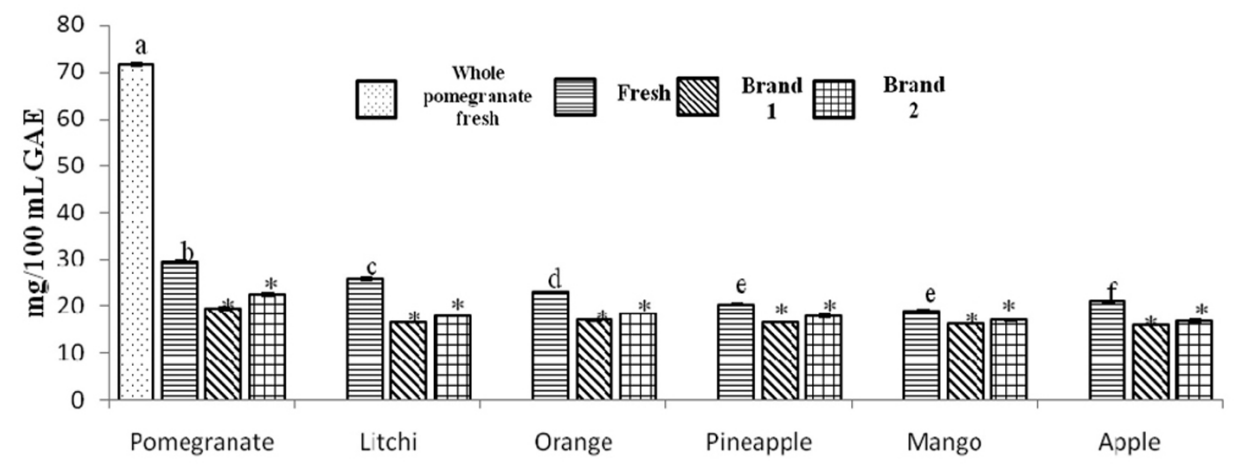

Figure 2. Total phenolic content (TPC) (mg/100 ml gallic acid equivalents) of fresh fruit juices and packaged juices. Each value represents mean $\pm \mathrm{SEM}, n=5$. Values with different superscripts (a-f) differ significantly at $P<0.0001$. TPC of packaged juices marked with $\left(^{*}\right)$ are significantly $(P<0.001)$ different compared to their fresh fruit counterparts.

methods involve the principle of conversion or disappearance of a chromogen of radical nature by antioxidants present in the analytical sample. FRAP assay was performed to measure the antioxidant activity of fruit juices. The assay measures the ability of antioxidant compounds to reduce $\mathrm{Fe}$ (III) to $\mathrm{Fe}$ (II) under acidic condition ( $\mathrm{pH}$ 3.6). Among fresh fruit juices, pomegranate had the highest antioxidant activity (Figure 1). The order of antioxidant activity of other fruit juices was litchi $>$ mango $>$ pineapple $>$ apple $>$ orange.

Many other studies have also shown the high antioxidant capacity and phenolic content of pomegranate juice, much higher than most other fruit juices and beverages $^{15-17}$. The prominent antioxidant compounds in pomegranate juice are hydrolysable tannins, anthocyanins and ellagic acid ${ }^{15}$. Due to its high antioxidant activity, pomegranate juice has been recommended as a preventive measure for coronary heart disease ${ }^{18}$, and is also reported to augment the chemotherapeutic effects on human prostate cancer ${ }^{19}$.

Litchi also showed very high antioxidant activity (Figure 1). Many studies have reported significant amount of polyphenols, flavonoids and anthocyanins in litchi peri$\operatorname{carp}^{20}$ and attributed anti-inflammatory, anti-carcinogenic and immune-modulatory properties to these phenols ${ }^{21-23}$. In this study we have compared the antioxidant property of litchi aril that is used for making juice with other fresh fruit juices and its commercial counterpart. The variations in antioxidant activities of different types of fruit juices in the present study from those reported in the past might be due to maturity index of the selected fruits, parts of the fruits used, technique used for juice extraction, sample preparation and handling, and also exposure to oxygen or light during laboratory analysis ${ }^{24-27}$. 


\section{RESEARCH COMMUNICATIONS}

Compared to packaged fruit juices of both the commercial brands, all fresh fruit juices had significantly higher antioxidant activity as estimated by FRAP assay (Figure 1). In a similar study, Wern et al. ${ }^{28}$ reported that commercial fruit juices were not a good source of antioxidants compared to fresh fruit juices.

TPC of fruit juice samples was estimated using FolinCiocalteu assay. The assay is based on the reduction of FCR by phenolic compounds under alkaline conditions. The absorbance is directly proportional to the concentration of phenolic compounds, which is represented by the intensity of blue colour produced in each solution ${ }^{29}$. The highest TPC content was present in fresh pomegranate among all the fruits (Figure 2). TPC of whole pomegranate, including rind was much higher than that of fresh pomegranate juice extracted from aril only. This was also seen in the study conducted on Persian pomegranate by Shams Ardekani et al. ${ }^{30}$. In conformation with our studies, Gözlekçi et al. ${ }^{31}$ also reported high TPC in peels followed by arils. TPC was found to be significantly high in fresh fruit juices compared to packaged juices, corresponding to the antioxidant activity as measured by FRAP. Similarly, higher total phenolic compounds were reported in freshly extracted fruit juices by Mahdavi et al. ${ }^{32}$.

The findings from the present study suggest that fresh fruit juices are a much better source of antioxidants when compared to packaged juices. Their regular consumption can have a beneficial effect and protect us from many non-communicable diseases. Commercial juices, although easily available and attractive, could be considered as a replacement for aerated drinks but not for fresh fruit juices. Among fresh fruit juices, pomegranate has the highest total phenols and antioxidant activity. Moreover, pomegranate juice, including rind has higher antioxidant activity compared to juice extracted from arils only. Litchi, otherwise less known for its antioxidant property, can also be considered as a good source of antioxidants.

1. Duracková, Z., Some current insights into oxidative stress. Physiol. Res., 2010, 59(4), 459-469; Epub November 2009.

2. Alfadda, A. A. and Sallam, R. M., Reactive oxygen species in health and disease. J. Biomed. Biotechnol., 2012, 2012, 1-14; doi: 10.1155/2012/936486, Epub 8 August 2012.

3. Gupta, R. K. et al., Oxidative stress and antioxidants in disease and cancer: a review. Asian Pac. J. Cancer Prev., 2014, 15(11), 4405-4409.

4. Sun, J., Chu, Y. F., Wu, X. and Liu, R. H., Antioxidant and antiproliferative activities of common fruits. J. Agric. Food Chem., 2002, 50(25), 7449-7454.

5. Guarnieri, S., Riso, P. and Porrini, M., Orange juice vs vitamin C: effect on hydrogen peroxide-induced DNA damage in mononuclear blood cells. Br. J. Nutr., 2007, 97(4), 639-643.

6. Lim, Y. Y., Lim, T. T. and Tee, J. J., Antioxidant properties of several tropical fruits: a comparative study. Food Chem., 2007, 103(3), 1003-1008.

7. World Health Organization, Diet, nutrition and prevention of chronic diseases. WHO Technical Report Series 916. 2003; https://apps.who.int/iris/bitstream/handle/10665/42665/WHO_TRS 916.pdf; jsessionid=33BBDB509AAE845C5E29F15CCE4C5EA7?se quence $=1$ (last accessed on 8 June 2019).

8. Mukherjee, A., Dutta, S. and Goyal, T. M., India's phyto nutrient summary: Executive summary, 2016; http://icrier.org/pdf/India Phytonutrient_Report_Ex_summary.pdf (last accessed on 5 June 2019).

9. Savatovic, S. M., Tepic, A. N., Sumic, Z. M. and Nikolic, M. S., Antioxidant activity of polyphenols enriched apple juices. Acta Period. Technol., 2009, 40(40), 95-102.

10. Ndhlala, A. R., Moyo, M. and Staden, J. V., Natural antioxidants: fascinating or mythical biomolecules? Molecules, 2010, 15, 69056930.

11. Benzie, I. F. F. and Strain, J. J., The ferric reducing ability of plasma (FRAP) as a measurement of 'antioxidant power': FRAP assay. Anal. Biochem., 1996, 239, 70-76.

12. Abountiolas, M. and Nunes, C. N., Polyphenols, ascorbic acid and antioxidant capacity of commercial nutritional drinks, fruit juices, smoothies and teas. Int. J. Food Sci. Technol., 2018, 53, 188-198.

13. Singleton, V. and Rossi, J. A., Colorimetry of total phenolics with phosphomolybdic-phosphotungstic acid reagents. Am. J. Enol. Viticult., 1965, 16, 144-158.

14. Sasic-Keskin, I. et al., Total phenolic content and antioxidant capacity of fruit juices. Bull. Chem. Technol. Bosnia Herzegovina, 2012, 39, 25-28.

15. Gill, M. I., Tomás-Barberán, A., Hess-Pierce, B., Holcroft, D. M. and Kader, A. A., Antioxidant activity of pomegranate juice and its relationship with phenolic composition and processing. $J$. Agric. Food Chem., 2000, 48, 4581-4589.

16. Seeram, N. P., Aviram, M., Zhang, Y., Henning, S. M., Feng, L., Dreher, M. and Heber, D., Comparison of antioxidant potency of commonly consumed polyphenol-rich beverages in the United States. J. Agric. Food Chem., 2008, 56, 1415-1422.

17. Nuncio-Jáuregui, N., Calín-Sánchez, Á., Vázquez-Araujo, L., Pérez-López, A. J., Frutos Fernández, M. J. and CarbonellBarrachina, Á. A., Processing pomegranates for juice and impact on bioactive components. In Processing and Impact on Active Components in Food, Elsevier, London, UK, 2015, pp. 629-636.

18. Basu, A. and Penugonda, K., Pomegranate juice: a heart-healthy fruit juice. Nutr. Rev., 2009, 67, 49-56.

19. Malik, A., Afaq, F., Sarfaraz, S., Adhami, V., Syed, D. and Mukhtar, H., Pomegranate fruit juice for chemoprevention and chemotherapy of prostate cancer. Proc. Natl. Acad. Sci. USA, 2005, 102, $14813-14818$

20. Zhao, M., Yang, B., Wang, J., Li, B. and Jiang, Y., Identification of the major flavonoids from pericarp tissues of lychee fruit in relation to their antioxidant activities. Food Chem., 2006, 98, 539544; doi:10.1016/j.foodchem.2005.06.028.

21. Prasad, N. K., Yang, B., Zhao, M., Wang, B. S., Chen, F. and Jiang, Y., Effects of high-pressure treatment on the extraction yield, phenolic content and antioxidant activity of litchi (Litchi chinensis Sonn.) fruit pericarp. Int. J. Food Sci. Technol., 2009, 44, 960-966; doi:10.1111/j.1365-2621.2008.01768.x.

22. Li, W. et al., Phenolic profiles and antioxidant activity of litchi (Litchi chinensis Sonn.) fruit pericarp from different commercially available cultivars. Molecules, 2012, 17, 14954-14967; doi:10.3390/molecules171214954.

23. Jiang, G. et al., Identification of a novel phenolic compound in litchi (Litchi chinensis Sonn.) pericarp and bioactivity evaluation. Food Chem., 2013, 136, 563-568; doi:10.1016/j.foodchem. 2012.08.089.

24. Wang, W. D. and Xu, S. Y., Degradation kinetics of anthocyanins in blackberry juice and concentrate. J. Food Eng., 2007, 82(3), 271-275.

25. Burin, V. M., Falcão, L. D., Gonzaga, L. V., Fett, R., Rosier, J. P. and Bordignon-Luiz, M. T., Colour, phenolic content and antioxidant activity of grape juice. Ciênc. Tecnol. Aliment., 2010, 30(4), 1027-1032; http://dx.doi.org/10.1590/S0101-20612010000400030 
26. Gull, J., Sultana, B., Anwar, F., Naseer, R., Ashraf, M. and Ashrafuzzaman, M., Variation in antioxidant attributes at three ripening stages of guava (Psidium guajava L.) fruit from different geographical regions of Pakistan. Molecules, 2012, 17(3), 3165-3180.

27. Sreekumar, S., Sithul, H., Muraleedharan, P., Azeez, J. M. and Sreeharshan, S., Pomegranate fruit as a rich source of biologically active compounds. Biomed. Res. Int., 2014, Article ID. 686921; http://dx.doi.org/10.1155/2014/686921.

28. Wern, K. H., Haron, H. and Keng, C. B., Comparison of total phenolic contents (TPC) and antioxidant activities of fresh fruit juices, commercial 100\% fruit juices and fruit drinks. Sains Malays., 2016, 45(9), 1319-1327.

29. Huang, D., Ou, B. and Prior, R. L., The chemistry behind antioxidant capacity assays. J. Agric. Food Chem., 2005, 53(6), 18411856.

30. Shams Ardekani, M. R. et al., Comparative antioxidant activity and total flavonoid content of Persian pomegranate (Punica granatum L.) cultivars. Iran. J. Pharm. Res., 2011, 10(3), 519-524.
31. Gözlekçi, Ş., Saraçoğlu, O., Onursal, E. and Özgen, M., Total phenolic distribution of juice, peel, and seed extracts of four pomegranate cultivars. Pharmacogn. Mag., 2011, 7(26), 161-164; doi: 10.4103/0973-1296.80681.

32. Mahdavi, R., Nikniaz, Z., Rafraf, M. and Jouyban, A., Determination and comparison of total polyphenols and vitamin $\mathrm{C}$ contents of natural fresh and commercial fruit juices. Pak. J. Nutrition, 2010, 9(10), 968-972.

ACKNOWLEDGEMENTS. We thank the Principal, Maitreyi College, Delhi for encouragement and support. This work was funded by the Summer Internship Programme of Maitreyi College.

Received 23 July 2019; revised accepted 9 October 2019

doi: $10.18520 / \mathrm{cs} / \mathrm{v} 118 / \mathrm{i} 2 / 300-304$

\section{OURRENT SGIENGE \\ Display Advertisement Rates}

\begin{tabular}{|c|c|c|c|c|c|c|c|}
\hline India & \multicolumn{7}{|c|}{ Tariff (Rupees)* } \\
\hline \multirow[b]{2}{*}{ Size } & \multirow{2}{*}{$\begin{array}{c}\text { No. of } \\
\text { insertions }\end{array}$} & \multicolumn{2}{|c|}{ Inside pages } & \multicolumn{2}{|c|}{ Inside cover pages } & \multicolumn{2}{|c|}{ Back cover pages } \\
\hline & & $B \& W$ & Colour & $B \& W$ & Colour & B\&W & Colour \\
\hline \multirow{7}{*}{$\begin{array}{l}\text { Full page } \\
\left(\begin{array}{l}(H=23 \mathrm{~cm} ; \\
W=17.5 \mathrm{~cm})\end{array}\right.\end{array}$} & 1 & 18,000 & 30,000 & 25,000 & 40,000 & 35,000 & 45,000 \\
\hline & 2 & 33,000 & 55,000 & 47,000 & 76,000 & 65,000 & 86,000 \\
\hline & 4 & 62,000 & $1,05,000$ & 92,000 & $1,46,000$ & $1,25,000$ & $1,65,000$ \\
\hline & 6 & 90,000 & $1,50,000$ & $1,25,000$ & $2,00,000$ & $1,75,000$ & $2,25,000$ \\
\hline & 8 & $1,10,000$ & $1,87,000$ & $1,68,000$ & $2,65,000$ & $2,30,000$ & $3,00,000$ \\
\hline & 10 & $1,35,000$ & $2,25,000$ & $1,98,000$ & $3,15,000$ & $2,70,000$ & $3,60,000$ \\
\hline & 12 & $1,80,000$ & $3,00,000$ & $2,50,000$ & $4,00,000$ & $3,50,000$ & $4,50,000$ \\
\hline \multirow{7}{*}{$\begin{array}{l}\text { Half page } \\
\begin{array}{l}(\mathrm{H}=11 \mathrm{~cm} ; \\
W=17.5 \mathrm{~cm})\end{array}\end{array}$} & 1 & 10,000 & 18,000 & \multirow{7}{*}{$\begin{array}{l}\text { Quarter page } \\
\begin{array}{l}(\mathrm{H}=11 \mathrm{~cm} \\
W=8 \mathrm{~cm})\end{array}\end{array}$} & \multirow{2}{*}{$\begin{array}{c}\text { No. of } \\
\text { insertions }\end{array}$} & \multicolumn{2}{|c|}{ Inside pages } \\
\hline & 2 & 19,000 & 33,000 & & & B\&W & Colour \\
\hline & 4 & 35,000 & 62,000 & & 1 & 6,000 & 12,000 \\
\hline & 6 & 50,000 & 90,000 & & 6 & 30,000 & 60,000 \\
\hline & 8 & 60,000 & $1,10,000$ & & 12 & 60,000 & $1,20,000$ \\
\hline & 10 & 72,000 & $1,35,000$ & & & & \\
\hline & 12 & $1,00,000$ & $1,80,000$ & & & & \\
\hline $\begin{array}{c}\text { Other } \\
\text { Countries }\end{array}$ & \multicolumn{7}{|c|}{ Tariff (US \$) ${ }^{*}$} \\
\hline \multirow[b]{2}{*}{ Size } & \multirow{2}{*}{$\begin{array}{c}\text { No. of } \\
\text { insertions }\end{array}$} & \multicolumn{2}{|c|}{ Inside pages } & \multicolumn{2}{|c|}{ Inside cover pages } & \multicolumn{2}{|c|}{ Back cover pages } \\
\hline & & B\&W & Colour & $B \& W$ & Colour & $B \& W$ & Colour \\
\hline \multirow{2}{*}{$\begin{array}{l}\text { Full page } \\
(H=23 \mathrm{~cm} ; \\
W=17.5 \mathrm{~cm})\end{array}$} & 1 & 300 & 650 & 450 & 750 & 600 & 1000 \\
\hline & 6 & 1500 & 3000 & 2250 & 3500 & 3000 & 5000 \\
\hline \multirow{2}{*}{$\begin{array}{l}\text { Half page } \\
(\mathrm{H}=11 \mathrm{~cm} ; \\
\mathrm{W}=17.5 \mathrm{~cm})\end{array}$} & 1 & 200 & 325 & & & & \\
\hline & 6 & 1000 & 2000 & & & & \\
\hline
\end{tabular}

* $25 \%$ rebate for Institutional members

Note: For payments towards the advertisement charges, Cheque (at par/multicity) or Demand Drafts may be drawn in favour of 'Current Science Association, Bengaluru'.

Contact us: Current Science Association, C.V. Raman Avenue, P.B. No. 8001, Bengaluru 560080 or e-mail: csc@ias.ac.in

Last date for receiving advertising material: Ten days before the scheduled date of publication.

[The jurisdiction for all disputes concerning submitted articles, published material, advertisement, subscription and sale will be at courts/tribunals situated in Bengaluru city only.] 